\title{
Standardized headings as a foundation for semantic interoperability in EHR
}

\author{
Amra Halilovic ${ }^{1, a}$ and Annika Terner ${ }^{2}$ \\ ${ }^{1}$ Dalarna County Council, Falun, Sweden, amra.halilovic@ltdalarna.se \\ ${ }^{2}$ Uppsala County Council and Department of Public Health and Caring Sciences, Uppsala University, Uppsala, Sweden
}

\begin{abstract}
The new Swedish Patient Act, which allows patients to choose health care in county councils other than their own, creates the need to be able to share health-related information contained in electronic health records [EHRs) across county councils. This demands interoperability in terms of structured and standardized data. Headings in EHR could also be a part of structured and standardized data. The aim was to study to what extent terminology is shared and standardized across county councils in Sweden. Headings from three county councils were analyzed to see to what extent they were shared and to what extent they corresponded to concepts in SNOMED CT and the National Board of Health and Welfare's term dictionary [NBHW's TD). In total $41 \%$ of the headings were shared across two or three county councils. A third of the shared headings corresponded to concepts in SNOMED CT. Further, an eighth of the shared headings corresponded to concepts in NBHW's TD. The results showed that the extent of shared and standardized terminology in terms of headings across the studied three county councils were negligible.
\end{abstract}

Keywords. Terminology, Snomed CT, Electronic Health Records, Healthcare Information and Management Systems, Health Informatics, Data Engineering.

\section{Introduction}

The 21 county councils in Sweden are responsible for ensuring that everyone living in Sweden has access to good health care. The principle of local self-government gives each county council the right to design health care services with reference to local conditions [1]. Most county councils have one joint electronic health record [EHR) system for all health-related documentation in hospitals, psychiatry and primary care.

The Patient Act 2104 [2] is a new law in Sweden, the aim of which is to empower patients and to promote patients' rights to privacy, self-determination, and participation. According to the law a patient has the right to choose health care in county councils other than their own which creates the need to be able to share healthrelated information in EHRs across county councils.

EHR is defined as an electronic record of healthrelated information on an individual which conforms to nationally recognized interoperability standards and which can be created, managed, and consulted by health care professionals across health care organizations. Health-related information means among others: treatment and discharge summaries, investigation results and reports, prescriptions and health care professional notes [3].

\footnotetext{
a Amra Halilovic: amra.halilovic@1tdalarna.se
}

The main keys to interoperability are structured and standardized data. The Patient Act has been the driving force towards interoperability in health care. Interoperability allows the right information to be available to the tight people at the right time across products and organisations [4].

\subsection{Interoperability and headings}

Interoperability for EHRs is defined here as the ability of EHRs to send, receive, share and interpret structured and standardized health-related information [5]. There are several categories of interoperability, e.g. technical, semantic, organizational and legal interoperability [6]. Semantic interoperability means that the information is unambiguously understood in content, meaning, and purpose by the receiver. This demands standardized terminology as a path to structured, encoded and on a semantic level interoperable health data [7].

To structure the data EHRs should have templates [811] which consist of headings in a tree-structure [12, 13]. The templates and headings support the user to enter collected data in a structured way [14] into larger or smaller parts [15]. They also provide collected data with context [16] because a heading briefly defines the data in 
the part as a label on a box [15]. An EHR without structure obstructs the possibility to find collected data about the patient when and where it is needed.

Headings constitute a crucial part of the terminology employed in EHRs. The headings are predefined according to medical specialists' [16-20] and professional groups' [16], [21-26] perceived needs of necessary information to provide high-quality health care [17]. When professional groups and medical specialties independently define headings there are risks for synonyms i.e. different terms for the same concept [22], [27-30] or for homonyms i.e. different concepts for the same term $[22,27]$. This has resulted in headings not being standardized.

The Swedish National Board of Health and Welfare (NBHW), mandated by the Government, has the objective to develop and provide health care with a standard in terms of Common Information Structure (CIS) including National Information Structure (NIS) and National Language for Specific Purposes (NLSP). NIS includes descriptions at an overall level of the health care process and the information to be dealt with during the process. NLSP consists of nationally agreed concepts and terms published in the NBHW's term dictionary (TD). It also consists of SNOMED CT's (translated into Swedish) established statistical classifications and code systems. Methods for the development, management, and rules for use are also included in the CIS [31].

\subsection{Problem}

The need to be able to share health-related information across county councils in Sweden has become more important since the new Patient Act came into force. A prerequisite for sharing health-related information across county councils is interoperability which demands structured and standardized data. Headings structure the data in the EHRs and are therefore a crucial part of the terminology employed in the EHRs. However, to fulfill the request for standardized data the same terminology must be employed by all the county councils sharing health-related information. The question is: Do county councils employ the same terminology?

\section{Aim}

The aim of this paper is to study to what extent terminology is shared and standardized across county councils in Sweden. The specific research questions were: To what extent are headings shared across county councils? To what extent do the identified shared headings correspond to concepts in SNOMED CT and NBHW's TD?

\section{Methods}

A descriptive design was chosen for the study. At the time of data collection all county councils in Sweden had implemented EHRs for hospitals, psychiatry, and primary care. Three of these county councils (County A, County $\mathrm{B}$, and County $\mathrm{C}$ ) were chosen for the study.

\subsection{Data collection and analyses}

In January 2016 administrators in the chosen counties with access to EHR databases were asked for the headings stored in the databases. The obtained headings were compiled into a spreadsheet data file. The data consisted of a total of 32,228 headings consisting of single terms, multiple terms, expressions, or phrases. The spreadsheet data file was used for calculations and descriptive statistics.

The headings studied were obtained from databases. No patient information or health care professional information were obtained for the study.

\subsubsection{Shared headings across the county councils}

The number of headings which county B and C shared with County $\mathrm{A}$ as well as the proportions of shared headings were calculated and described. The criterion for sharing a heading with County A was that the studied headings in County B and/or C were spelled exactly the same as in County A. Headings sharing the same meaning but not spelled exactly the same were in this study not considered as shared with County A.

\subsubsection{Shared headings corresponding to concepts in SNOMED CT and NBHW'S TD}

To examine how the shared headings corresponded to concepts in SNOMED CT and NBHW's TD each heading as a concept was searched for in SNOMED CT and NBHW's TD. A heading found in SNOMED CT or NBHW's TD as a concept with the same spelling, in an adequate category in SNOMED CT and with a similar description as the heading was deemed to have a corresponding concept in SNOMED CT and/or NBHW's TD.

\section{Results}

The collected data from County A included 588 headings, County B had 15,778 headings and County C had 15,862. When duplications were eliminated County B had 14,906 headings and County $\mathrm{C}$ had 5,809. These numbers of heading for each county are used in the presentation of the results.

\subsection{Shared headings across the county councils}

In total $41 \%(n=241)$ of County A's 588 headings were shared with County B and/or County C. All three counties shared 130 headings $(22 \%)$. County A shared 174 headings with County B and 197 headings with County C, see Table 1 . 
Table 1: The distribution of shared headings in proportion to each county's number of headings

\begin{tabular}{|c|c|c|c|}
\hline & $\begin{array}{c}\text { County A } \\
\mathbf{n = 5 8 8}\end{array}$ & $\begin{array}{c}\text { County B } \\
\mathbf{n = 1 4 9 0 6}\end{array}$ & $\begin{array}{c}\text { County C } \\
\mathbf{n = 5 8 0 9}\end{array}$ \\
\hline $\begin{array}{c}\text { County A } \\
\mathbf{n}=\mathbf{5 8 8}\end{array}$ & & $30 \%(174)$ & $34 \%(197)$ \\
\hline $\begin{array}{c}\text { County B } \\
\mathbf{n}=\mathbf{1 4 9 0 6}\end{array}$ & $1 \%(174)$ & & \\
\hline $\begin{array}{c}\text { County C } \\
\mathbf{n}=\mathbf{5 8 0 9}\end{array}$ & $3 \%(197)$ & & \\
\hline
\end{tabular}

\subsection{Shared headings corresponding to concepts in SNOMED CT and NBHW's TD}

In total $35 \%(n=86)$ of the 241 headings in County $A$, shared with County B and/or County C, corresponded to concepts in SNOMED CT and 13\% $(\mathrm{n}=31)$ corresponded to concepts in NBHW's TD. Thirteen headings $(5 \%)$ were found both in SNOMED CT and NBHW's TD, see Table 2. Further, in total $45 \%(n=59)$ of the 130 headings shared across the three counties corresponded to concepts in SNOMED CT and 15\% $(\mathrm{n}=20)$ corresponded to concepts in NBHW's TD. Ten headings (7\%) were found both in SNOMED CT and NBHW's TD, see Table 2.

Table 2: The distribution of shared headings corresponding to SNOMED CT and NBHW's TD in proportion to headings shared with County B and/or County C and headings shared with County B and C

\begin{tabular}{|c|c|c|c|}
\hline & $\begin{array}{c}\text { SNOMED } \\
\text { CT }\end{array}$ & $\begin{array}{c}\text { NBHW's } \\
\text { TD }\end{array}$ & $\begin{array}{c}\text { SNOMED CT \& } \\
\text { NBHW's TD }\end{array}$ \\
\hline $\begin{array}{c}\text { Headings shared } \\
\text { with County B and/ } \\
\text { or County C n=241 }\end{array}$ & $36 \%(86)$ & $13 \%(31)$ & $5 \%(13)$ \\
\hline $\begin{array}{c}\text { Headings shared } \\
\text { with County B and } \\
\text { C n=130 }\end{array}$ & $45 \%(59)$ & $15 \%(20)$ & $7 \%(10)$ \\
\hline
\end{tabular}

\section{Discussion}

The results show that the headings in County B and C to a negligible extent were shared with County A. Only a third of the shared headings correspond to concepts in SNOMED CT. Further, only an eighth of the shared headings correspond to concepts in NBHW's TD. Thirteen headings (5\%) of 241 shared headings were found both in SNOMED CT and NBHW's TD.

The study was based on a large set of data comprising 32,228 headings from three county councils. The headings in County $\mathrm{B}$ and $\mathrm{C}$ were compared to the headings in County A. County A had the smallest number of headings $(n=588)$ and the authors considered that this was sufficient to fulfil the aim in the study. Therefore the authors decided not to compare the headings between County B and County C. Further, there is the question of whether all these headings correspond to the needs of health and health care.

Semantic interoperability is crucial in EHRs. This was the basis for the decision to only accept concepts in SNOMED CT and terms in NBHW's TD with exactly the spelling as the shared headings; only under this criterion were the headings regarded as shared. However, the amount of standardized headings in the studied EHRs is negligible.

\subsection{Conclusion and Future Work}

The results show that the extent of shared and standardized terminology in terms of headings across the studied three county councils is negligible. Consequently, the studied county councils do not employ the same terminology. These headings are a crucial part of a standardized terminology and medical specialists and professional groups have lengthy experience of employing headings. However, common and standardized headings should be employed and shared between different EHRs. Therefore our recommendation is to use headings as a tool for implementing a National Language for Specific Purposes as NBHW's standard.

The plan for the next study is to involve all 21 county councils and analyze the extent headings with the same meaning (including headings not spelled exactly the same) are common across the counties.

\section{References}

[1] Socialstyrelsen. God vård - om ledningssystem för kvalitet och patientsäkerhet $i$ hälso- och sjukvården In: Socialstyrelsen, Stockholm (2006)

[2] European Commission. Semantic Interoperability for Better Health and Safer Healthcare. Research and deployment roadmap for Europe. In: Commission E, (2009)

[3] The National Alliance for Health Information Technology. Report to the Office of the National Coordinator for Health Information Technology on Defining Key Health Information Technology Terms, Available

at:

http://cdm16064.contentdm.oclc.org/cdm/ref/collection/p 266901 coll4/id/2086 (2008)

[4] M. Stroupe, What is EHR Interoperability and Why Should I Care? A reference document for Urgent Care and Occupational Health Providers (2011)

[5] Healthcare Information and Management Systems Society. Interoperability Definition and Background. Available

http://www.himss.org/ResourceLibrary/ResourceDetail.a spx?ItemNumber $=9265$ (2005)

[6] European Commission. Interoperability Solutions for European Public Administrations. Available at: http://ec.europa.eu/isa (2016)

[7] European Commission. eHealth Governance Initiative, Making Use of SNOMED CT: Key Questions And Status As Of September 2013. Available at: ec.europa.eu/health/ehealth/events/ev_20131119_en.htm. 
[8] D. Andreen, L. Dobie, J. Jasperson, T. Lucas, C. Wubbenhorst. The conversion to electronic hospital notes at Mayo Clinic. Overcoming barriers and challenges. JHIM, 24(3), pp. 57-64 (2010)

[9] K. Bernstein, M. Bruun-Rasmussen, S. Vingtoft, S. K. Andersen, C. Nøhr. Modelling and implementing electronic health records in Denmark. IJMI, 74(2), pp 213-20 (2005)

[10] D.R. Boulware, A.S. Dekarske, G.A. Filice, Physician Preferences for Elements of Effective Consultations. JGIM, 25(1), pp:25-30 (2010)

[11] V.K. Goradia. Electronic Medical Records for the Arthroscopic Surgeon. Arthroscopy: The Journal of Arthroscopic and Related Surgery, 22(2), pp 219-24 2006 [12] J.C. Denny, Iii A. Spickard, K.B. Johnson, N.B. Peterson, J.F. Peterson, R.A. Miller. Evaluation of a Method to Identify and Categorize Section Headers in Clinical Documents. JAMIA, 16(6), pp 806-15 (2009)

[13] E. Törnvall, S. Wilhelmsson, Nursing documentation for communicating and evaluating care. JCN, 17(16), pp 2116-24. (2008)

[14] C. Cusack, Electronic Health Records and Electronic Prescribing: Promise and Pitfalls. OBSTET GYN CLIN N AM, 35(1), pp 63-79 (2008)

[15] M. Nordman, Överskrift, titel, namn eller rubrik? Några beteckningar i teori och praktik. In: Nuopponen A TB, Myking J, editor. I terminologins tjänst Festskrift för Heribert Picht på 60-årsdagen Vaasa: Vasa universitet, pp. 110-7 (2000).

[16] K. Häyrinen, K. Harno, P. Nykänen, Use of headings and classifications by physicians in medical narratives of EHRs: An evaluation study in a Finnish hospital. ACI, 2(2), pp 143-57 (2011)

[17] H. Ahlfeldt, M. Ehnfors, L. Ridderstolpe, Towards a Multi-professional Patient Record - A Study of the Headings Used in Clinical Practice. (1999). Available at: http://citeseerx.ist.psu.edu

[18] A.B. De Luna, G. Wagner, Y. Birnbaum, K. Nikus, M. Fiol, A. Gorgels, et al. A new terminology for left ventricular walls and location of myocardial infarcts that present $Q$ wave based on the standard of cardiac magnetic resonance imaging: A statement for healthcare professionals from a committee appointed by the International Society for Holter and Noninvasive Electrocardiography. Circulation, 114(16), pp. 1755-60 (2006)

[19] A.J. Maxwell, N.T. Ridley, G. Rubin, M.G. Wallis, F.J. Gilbert, M.J. Michell, The Royal College of Radiologists Breast Group breast imaging classification. CLIN RADIOL, 64(6), pp. 624-7. (2009)

[20] M. Schargus, F. Grehn, The European Glaucoma Society Glaucocard project: Improved digital documentation of medical data for glaucoma patients based on standardized structured international datasets. Albrecht Von Graefes Arch Klin Exp Ophthalmol, 246(12), pp. 1757-68 (2008)

[21] A. Ehrenberg, M. Ehnfors, I. Thorell-Ekstrand, Developing a national integrated classification of health care interventions in Sweden. IJMI, 74(11-12), pp. 973-9 (2005)

[22] J. Ozbolt, M.L. Wilson, D O'Brien, Much Ado About Terminology Standards. J. Perianesth. Nurs., 22(4), pp. 280-4 (2007)

[23] A. Thoroddsen, M. Ehnfors, A. Ehrenberg, Content and Completeness of Care Plans After Implementation of Standardized Nursing Terminologies and Computerized Records. CIN, 29(10), pp. 599-607 (2011)

[24] American Occupational Therapy Association. Uniform terminology for occupational therapy. Third edition. Am J Occup Ther., 48(11), pp. 1047-54 (1994)

[25] R. Buyl, M. Nyssen, Structured electronic physiotherapy records. IJMI, 78(7), pp. 473-81. (2009)

[26] K.R. Goeg, R. Chen, A.R. Hojen, P.Elberg, Content analysis of physical examination templates in electronic health records using SNOMED CT. IJMI, 83(10), pp. 736-49 (2014)

[27] T. Watkins, R. Haskell, C. Lundberg, J. Brokel, M. Wilson, N.Hardiker, Terminology use in electronic health records: basic principles, Urol Nurs, 29(5), pp. 321-6; quiz 7. (Sep-Oct 2009)

[28] A. Tapuria, D. Kalra, S.Kobayashi, Contribution of Clinical Archetypes, and the Challenges, towards Achieving Semantic Interoperability for EHRs. HIR, 19(4), pp. 286-92 (2013)

[29] J. Zeleznik, B. Agard-Henriques, B. Schnebel, D.L. Smith, Terminology Used by Different Health Care Providers to Document Skin Ulcers: the Blind Men and the Elephant. Journal of WOCN, 30(6), pp. 324-33. (2003)

[30] A-B. Jensdóttir, P. Jónsson, A. Noro, E. Jonsén, G. Ljunggren, H. Finne-Soveri, et al. Comparison of nurses' and physicians' documentation of functional abilities of older patients in acute care - Patient records compared with standardized assessment. SJCS, 22(3), pp. 341-7 (2008)

[31] Socialstyrelsen. Nationell informationsstruktur (2016) Available at: http://www.socialstyrelsen.se/nationellehalsa/nationellinf ormationsstruktur. 